Ibero-American cities: capture and revitalization of its historic vestiges
| RESUMEN |

La ciudad contemporánea crece desmedidamente, desbordando no solo los límites establecidos, sino las disposiciones normativas propuestas para regular su desarrollo. En las ciudades iberoamericanas este fenómeno es tan evidente que casi no hay excepciones, como no sean algunos fragmentos especialmente ataviados para el turismo. Ahí están Ouito, La Habana, Buenos Aires o Salvador de Bahía. Todas ellas, incluyendo Santiago de Chile, han sido presa de la avidez inmobiliaria, sobre todo en la segunda mitad del siglo XX. Y en cada caso se ha hecho patente la progresiva desfiguración de la imagen de los respectivos centros históricos.

\section{| ABSTRACT |}

The contemporary city grows excessively, overpassing not only the established limits, but also the proposed coding provisions to regulate its development. In Latin American cities, this phenomenon is quite obvious, with almost no exception but a few fragmented cases adapted for tourism, such as puito, La Habana, Buenos Aires or Salvador de Bahía. All of these cities have been subject to real estate development and speculation, especially along the second half of the twentieth century, including Santiago de Chile. Their historic districts have undergone progressive transformations that have distorted their very image.

\title{
Ciudades iberoamericanas: captura y revitalización de sus vestigios históricos
}

Cuando Apollinaire escribió que había que prepararles a la hiedra y al tiempo unas bellas ruinas no pensó, seguramente, que era necesario aspirar a una ciudad inerte y momificada. Pero comprendía que en la conformación del paisaje construido, la historia también puede tener cabida.

El dilema siempre seguirá siendo el cómo resolver la confrontación entre lo nuevo y lo antiguo, entre las formas tradicionales y las contemporáneas. Los arquitectos que habitualmente intervienen los edificios históricos no son los especialistas y, por lo mismo, guardan alguna distancia emocional con los inmuebles ya consagrados por la historia. Pareciera que no se resignan a aceptar las leyes morfológicas que los definen y por eso persisten en subvertirlas.

¿Será mejor intentar la mimesis o buscar la colisión de formas, contraponiendo a lo antiguo el sello de la era contemporánea? Es un hecho que ambos peligros acechan persistentemente a la ciudad en sus fragmentos de valor histórico o arquitectónico.
Un ejercicio enteramente especulativo permite dejar en claro que toda ciudad contemporánea está expuesta a un doloroso proceso de desnaturalización, si no se pone atajo a las nocivas acciones que estallan sin aviso en cualquier punto de su damero. Se demuestra que el núcleo central pudiera convertirse, por una parte, en un museo habitado si se orientan a un conservacionismo exacerbado. Por otra, puede llegar a ser otra ciudad, con mínimas huellas de lo que fue, si se desconocen sistemáticamente sus méritos arquitectónicos y urbanos.

Pero la necesidad de densificación progresiva ha estimulado, para mal de la ciudad, la construcción en altura. Y el mal no es la altura en sí misma, sino la falta de una planificación integral, en la que la escala urbana resulta ser un factor determinante. La ciudad crece verticalmente, pero a borbotones, arrojando resultados a menudo aberrantes. Lo que antes era excepción, ya se convierte en una ley: la discontinuidad y la decepcionante ausencia de euritmia, ese tan apreciado bien que habla de

Arquitecto, Universidad de Chile (1971). Diploma en Restauración Arquitectónica y Urbana, Instituto de la Vivienda Español. Madrid, España. 1973. Curso de Especialización en Trabajos de Restauración Arquitectónica, Madrid España, Servicio de Monumentos y Conjuntos del Ministerio de la Vivienda Español. Madrid, España, 1973 Curso interamericano de Restauración de Bienes Culturales, Escuela Nacional de Conservación, Restauración y Museografía (ex Convento Churubusco, México D. F., México) 1977-1978. Maestría en Restauración de Monumentos (Primer Año), Escuela Nacional de Conservación, Restauración y Museografía, México D. F., México, 1977-1978. Doctor en Arquitectura (Universidad Politécnica de Madrid, 2010). Miembro de ICOMOS-Chile. 
buena disposición y correspondencia de las diversas partes de un todo artístico.

Los elementos referenciales -aquellos que orientan y adicionalmente dan un sello particular a cada fragmento de ciudad- han ido desapareciendo conforme son absorbidos por las transformaciones. Desde luego, las torres de las iglesias ya no emergen como hitos urbanos: la mayor parte de ellas es objeto de asfixia y termina sobrepasada en altura por los rascacielos impiadosamente dispuestos a distancias nada generosas.

La arquitecta argentina Marina Waisman afirma que "en las ciudades europeas el lento ritmo de las transformaciones permite que se proponga el análisis de los tipos históricos como base para la proyectación de la ciudad, considerándolos como la materia prima más sólida del tejido urbano" [1].

En las ciudades latinoamericanas, en cambio, e fenómeno es enteramente diverso: las ciudades se encuentran en perenne y acelerado proceso de cambio. La relación del edificio con su entorno resulta casi siempre nula o, en el mejor de los casos, menoscabada. Lo grave es que cuando se renuncia a intervenir el entorno se establece una forma de silencio. Un silencio que se podría denominar "silencio social", siguiendo la terminología de la arquitecta Waisman.

Las causas de la indiferencia a la historia la explica esa absurda necesidad de trazar urgentes proyectos de futuro, generalmente colosales y, por lo mismo, casi siempre inalcanzables. El resultado es una suerte de imagen fragmentada, un collage que se lee a sobresaltos y que va carcomiendo la ciudad desde sus entrañas. Un mosaico de estilos, de formas, de volúmenes yuxtapuestos sin más orden que el que regala el azar. De allí las trazas que hoy aparecen inconclusas, de allí los conjuntos mutilados.
Una buena parte de las ciudades

latinoamericanas es víctima de la discontinuidad, reflejo de un poderoso sentimiento de inseguridad y de impaciencia. No existe una convicción plena de las capacidades propias. Se explican así las interrupciones, las rupturas, los brutales desgarramientos de los tejidos que ofrecían un promisorio y natural crecimiento. Se superponen las soluciones con una desapoderada soberbia y con un menosprecio absoluto de su antecedente. $Y$ todo es un comenzar de nuevo, como si el escenario fuese un erial permanente.

Julián Marías sostiene que "la ciudad que tarda en hacerse (por eso no es caprichosa) dura mucho tiempo. Excepto en su fase de fundación, cuando todavía no es ciudad, es siempre antigua. Normalmente el individuo vive en una ciudad que no han hecho sus coetáneos, sino sus antepasados. Es cierto que la transforma y modifica. Sobre todo, la usa a su manera, descubriendo en ello su vocación peculiar, pero, por lo pronto es una realidad, recibida, heredada, histórica. Es decir, ni más menos que la sociedad misma. Es difícil de entender, por eso es profunda, particularmente reveladora" [2].

Puestos a observar, efectivamente los elementos recurrentes de la ciudad actual son los ortoprismas que las inmobiliarias se han dedicado a multiplicar con un entusiasmo inquietante. Hace un siglo atrás, campeaban los edificios de dos pisos, con un repertorio formal que tendía a adscribirse a los cánones neoclásicos o historicistas. Y aquellos que decidían no calzarse ese sayo figurativo, al menos se sometían -aun cuando fuera por limitaciones técnicas- a la escala urbana predominante.

La invasión de las torres habitacionales es incontenible. Proliferan como la mala hierba, tan pronto advierten que la legalidad no está

[1] Waisman, Marina (1993). El interior de la Historia. Historiografía arquitectónica para uso de latinoamericanos. Escala, Bogotá, p. 44

[2] Marías, Julián (1956). "La estructura social". Madrid, citado por Fernando Chueca Goitía (1968) en Breve historia del urbanismo, Alianza Editorial S.A., Madrid. 
de la ciudad. Lo único que cabe, entonces, es preservarlos de la mejor manera posible, sin que ello signifique momificarlos a perpetuidad. La consigna lógica para un habitante sensato es, sin duda, rehabilitarlos.

Los valores que encierran los sectores de valor reconocido -sean de orden artístico, arquitectónico o histórico- sugieren precisamente eso: poner en marcha proyectos de rehabilitación. Su pérdida supondría el fin del espíritu que animó ese barrio, comuna o ciudad, el término de aquello que le distingue de otras unidades equivalentes. Es lo que le hace inconfundible.

\section{LA OBSOLESCENCIA, UN MAL INEVITABLE}

Evidentemente, la obsolescencia funcional, física y económica es la raíz del problema de la conservación del patrimonio urbano y arquitectónico. Estos procesos - difíciles de evitar y también de revertir- se combinan para causar el deterioro de los edificios históricos y los espacios públicos que les rodean.

Este fenómeno, que también se extiende a los espacios públicos, surge cuando las estructuras - los lugares ya no satisfacen las demandas para las cuales fueron diseñados originalmente.

Después de la implantación de la arquitectura moderna en las unidades de relleno, las ciudades han tenido que aceptar nuevos tipos arquitectónicos, llevando a remolque las corrrespondientes manifestaciones sociales. Sobre esa trama languidecen, casi sin atenuantes, los edificios históricos. Cuando logran superar el primer momento -eluden el avance del bulldozer-, los gobiernos adoptan un enfoque más activo en materia de conservación. Promulgan leyes o crean comisiones de defensa del patrimonio. Pero tan pronto se enfrentan a necesidades sociales acuciantes, escasean los recursos para financiar el mantenimiento y la recuperación del patrimonio urbano. La carencia de fondos se ve, con frecuencia, agravada por la falta de experiencia técnica. Eso explica que, en la mayoría de los casos, las buenas intervenciones sean más o menos excepcionales. Lo difícil es el equilibrio justo entre las funciones que desempeñan el sector público y el sector privado. A menudo las intervenciones públicas, orientadas a conservar el patrimonio, terminan por desplazar, en buena medida, al sector privado, que puede cumplir un gravitante rol en el proceso. Y el desenlace es casi siempre el mismo: el Estado se muestra impotente para conservar, con sus limitados recursos, un gran número de edificios y espacios públicos.

Con todo, el mundo de hoy día parece depender de los grupos que tienen el poder en sus manos. Decisiones de todo orden les compete. El escenario urbano, por desgracia, no escapa de este fatalismo. Las autoridades y los técnicos son sobrepasados por la velocidad con que se precipitan los hechos.

Comoquiera que sea, la ciudad es un organismo inconteniblemente dinámico, cuyas transformaciones serán siempre un hecho inevitable. Hay que procurar, no obstante, que esas transformaciones sean lo menos agresivas que se pueda. Es un buen augurio, en ese sentido, el que las autoridades reconozcan, de cuando en cuando, el daño que producen las espurias operaciones que desde sus propios cargos han aceptado.

\section{LAS CIUDADES AMERICANAS, UN PERMANENTE CAMPO DE EXPERIMENTACIÓN}

Bien se sabe que las ciudades americanas se ciñeron a las ordenanzas de Felipe II del 13 de julio de 1573, que a partir de la plaza mayor definía la retícula de calles ${ }^{[3]}$.
Promediaba el siglo xx cuando se produjeron crecimientos explosivos en todas las ciudades americanas. A la migración campo-ciudad se sumó el cambio que experimentaba el patrón de vida de aquellos habitantes que tradicionalmente ocuparon los cascos históricos. Con celeridad descontrolada se destruía y se creaban obras nuevas, menospreciando sin escrúpulos el marco existente. Aparecieron las discontinuidades del paisaje urbano, disolviendo poco a poco un tejido que hasta entonces lucía razonablemente armónico y coherente.

Por fortuna, se hicieron sentir -tímidamente al comienzo- los ecos que provenían de Europa tras la fundación de UNESCO, en 1945. Algunas naciones habían decretado leyes de protección para sus monumentos: Francia, en 1911 ; España, en 1926. México fue el primer país americano que se sumó a los esfuerzos internacionales para la Conservación de los Monumentos y Ciudades Históricas, participando en la Conferencia de las Naciones Unidas sobre Viajes Internacionales y Turismo, celebrada en Roma en 1963. Y llegó la Carta de Venecia, un año después ${ }^{[4]}$

Se sucedieron los encuentros: la Reunión sobre Conservación y Utilización de Monumentos y Lugares de Interés Histórico y Artístico, de 1967 en Quito; el Coloquio Internacional sobre la Conservación, Preservación y Valoración de los Monumentos y Sitios en función del Desarrollo del Turismo Cultural, acaecido en Oxford, en 1969.

Con todo, la diversidad de situaciones que caracterizan los centros históricos de las ciudades iberoamericanas hace difícil un análisis común y un tratamiento homogéneo a sus problemas ${ }^{[5]}$

[3] Suárez, Alejandro. Ciudadan@latin@ [http://habitat.aq.upm.es/boletin/n23/aasua.html].

[4] Sánchez López, Martha Rosalía. Op. cit., p. 150.

[5] Carrión, Fernando (2003). "Centros históricos y actores patrimoniales". Cuadernos de la CEPAL № 88, Santiago, p. 130 
1. Centro histórico de Quito, Ecuador (Creative Commons, Fuente: www.flickr.com/photos/queulat00/).

\section{EL CENTRO HISTÓRICO DE QUITO: UNA CONSOLIDACIÓN RAZONADA}

Merece la pena destacar positivamente el caso de Quito: sus autoridades fueron capaces de involucrar a los ciudadanos en el proceso de recuperación del núcleo fundacional y se valieron, para ello, de una comisión de Áreas Históricas. Esta institución estuvo integrada, además, por los regidores de la ciudad, por el Colegio de Arquitectos y por representantes del Patrimonio Cultural. Lo importante es que los ciudadanos residentes en el casco antiguo tuvieron la posibilidad de acceder a préstamos blandos para la rehabilitación de sus propias viviendas.

En términos regulatorios, se procedió a la elaboración de un Plan Maestro del Casco Histórico, que incluyó la peatonalización del centro y la implementación de una red de transporte de trolebuses. En el proceso estuvieron también presentes las corporaciones privadas de administración de equipamientos culturales de importancia metropolitana (como el Museo de la Ciudad, por ejemplo). Se elaboraron, para el efecto, ordenanzas específicas destinadas a regular la intervención en las construcciones de valor patrimonial y en la recuperación de espacios públicos, tales como plazas inmediatas a conventos o edificios representativos.

En el camino hacia la consolidación de Quito como ciudad histórica fue necesario superar, sin embargo, algunos valladares de difícil elusión: entre ellos, el financiamiento y el transporte. El primero constituyó un desafío a la capacidad de gestión de una autoridad política que debía mostrar resultados positivos durante su período de gobierno; el transporte, por su parte, implicó la avenencia de la autoridad local con la nacional para contrarrestar la oposición del poderoso gremio de transporte de pasajeros de la ciudad. Al mismo tiempo, significó la puesta en funcionamiento de una solución de transporte de pasajeros que garantizara la detención del deterioro producto del tránsito vehicular y la contaminación atmosférica.






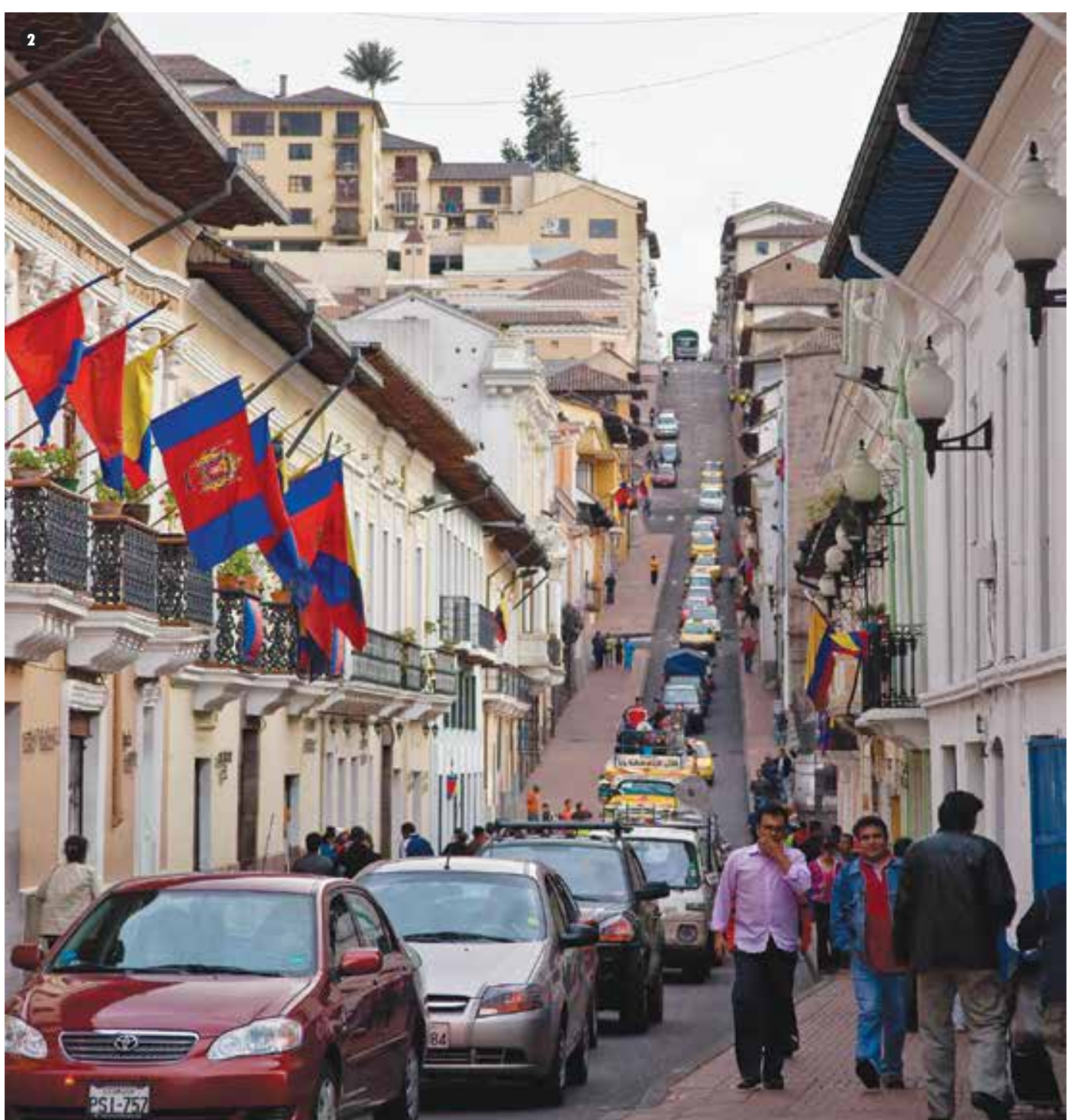

El resultado final de las acciones descritas es la revalorización del casco histórico como lugar de destino y residencia, aun cuando el proceso todavía no termina de consolidarse.

\section{EL DESPERTAR DE LA HABANA}

Fundada el 25 de julio de 1519, La Habana había acumulado un extraordinario patrimonio que fue crecientemente amenazado por la especulación inmobiliaria. Pero, después de la revolución, en Cuba se puso en marcha una singular experiencia urbana en la que especulador inmobiliario privado, hasta entonces protagonista en la planificación de la ciudad. Las empresas constructoras, que se habían afanado en sustituir el tejido histórico, desnaturalizando la imagen tradicional, dejaron de ser agentes de aniquilamiento y perversión.

La Universidad de San Jerónimo de la Habana, de las grandes universidades españolas en el continente-, fue irracionalmente reemplazada, definitivamente se marginó del proceso al en el Monasterio de Santo Domingo -la última en pleno corazón de La Habana Vieja, por un terminal de helicópteros; se demolieron, además, los edificios que rodean la catedral para convertirlos en aparcamientos de automóviles. Plazas como la de San Juan de Dios fueron arrasadas completamente para colocar, en el corazón del centro histórico, los primeros rascacielos. Aquel destructivo proceso solo se detuvo a contar de la segunda mitad de siglo pasado.

En este escenario, los criterios de gestión de la preservación del casco histórico de la ciudad de La Habana evolucionaron a lo largo del tiempo ${ }^{[6]}$

Como prioridad central se puso el acento en la conservación y restauración de edificios históricos, contando con el entusiasta apoyo de los especialistas. A partir de 1960 se restauraron y recuperaron edificios históricos de notable calidad.

La declaratoria de la ciudad de La Habana como Patrimonio de la Humanidad, en 1981, marcó el inicio de la recuperación de la ciudad antigua, desde una nueva óptica. La Dirección de Patrimonio Nacional de Cuba puso en marcha el Programa de La Habana y de las restauraciones parciales que había guiado durante largos años. $Y$ aun cuando entre 1989 y 1990 el país estuvo en una situación crítica -el transporte y la dotación de energía eléctrica fueron un desastre-, las condiciones permitieron que en 1993 se creara la Oficina del Historiador. Se trataba de un organismo autofinanciado, con personalidad jurídica propia y con recursos y facultades suficientes como para intervenir las construcciones del casco histórico de la ciudad de La Habana ${ }^{[7]}$. Se le otorgó un préstamo inicial de un millón de dólares y el usufructo de un impuesto del $5 \%$ de las entradas brutas de los ingresos del comercio y las empresas. De ello debía dar cuenta directamente al Jefe de Estado y al Consejo de Ministros.

6] Tello, María del Pilar. Op. cit., pp. 86-90.

[7] Tello, María del Pilar. Op. cit., p. 89 
3. Casco histórico de La Habana, Cuba (Fuente: Gonzalo Arze A.).

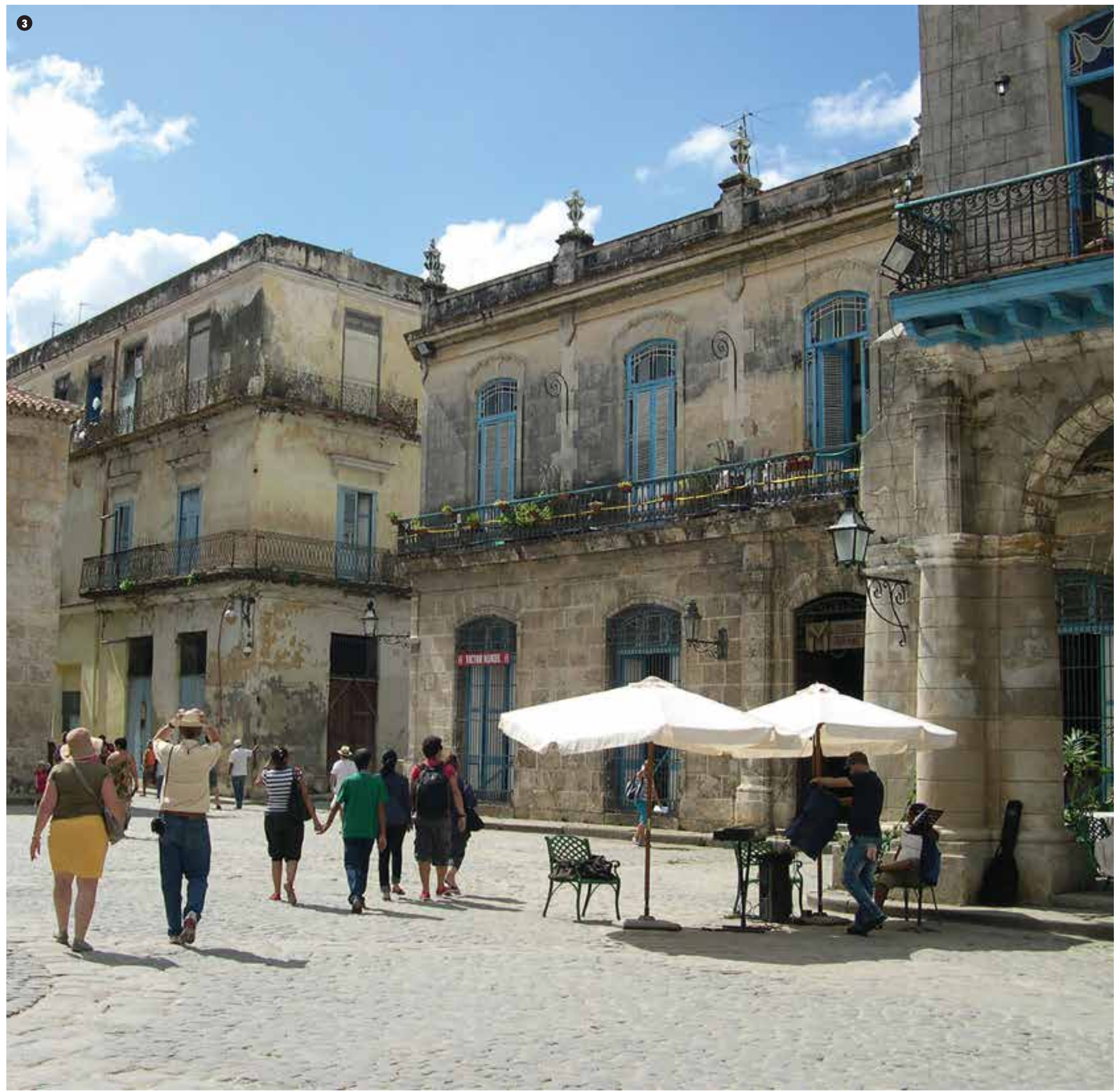




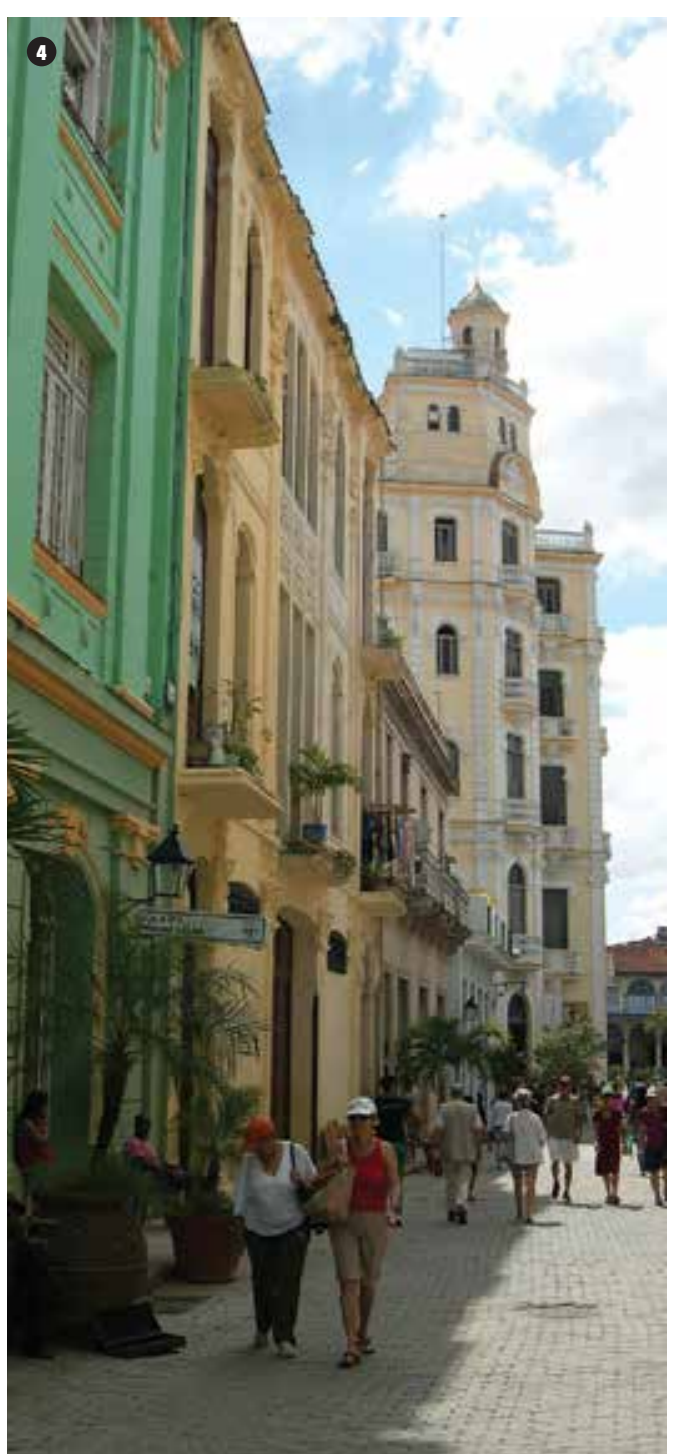

Uno de los propósitos centrales del plan era crear fuentes de laborales, entendiendo que la restauración de monumentos debía incorporar a la comunidad en todas sus acciones. Más que erradicar a las personas del centro histórico y convertirlo en un lugar de disfrute turístico, se hizo un esfuerzo por crearles puestos de trabajo. En cuatro años se dio empleo a más de 5.000 residentes.
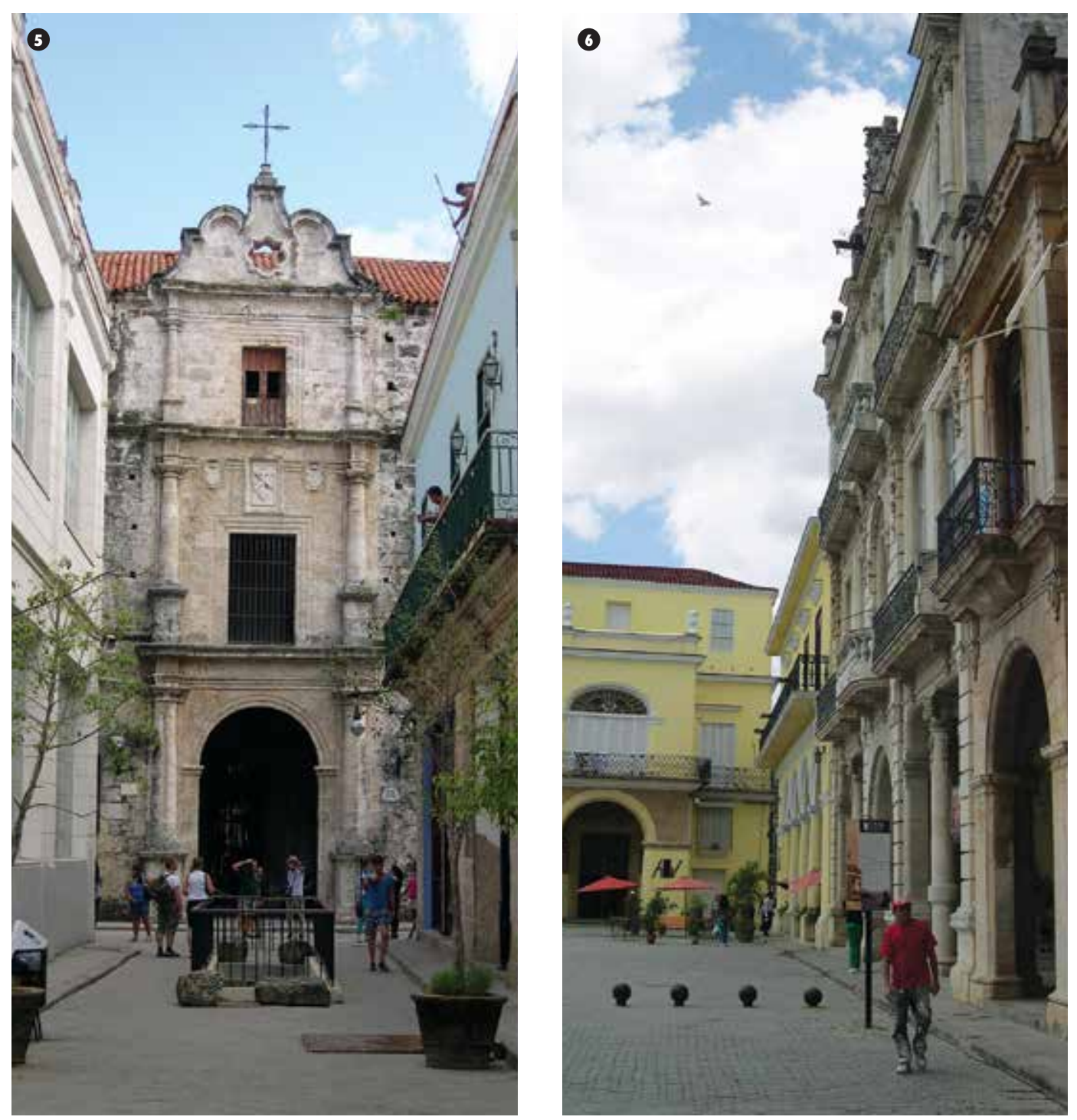

Este hecho se confirmó con el posicionamiento del casco histórico de la ciudad como destino turístico, de modo que las acciones de rehabilitación de la ciudad histórica se financiaron con las utilidades que proveía el propio sistema. Se generó, de esta manera, una cadena de efectos positivos a partir de la explotación del patrimonio.
Un producto adicional de ese círculo virtuoso fue la implementación de programas de educación, de hogares de ancianos y la asistencia a menores de edad ${ }^{[8]}$. Iniciativas que apuntan a la consecución de un casco histórico vivo, rehabilitado no solo en sus construcciones, sino también en la actividad de sus ocupantes.

[8] En 1996 se estimaba, producto del censo, que en el casco histórico de La Habana residían 70.600 habitantes. 
7. Puerto Madero, Buenos Aires, Argentina (Fuente: Constantino Mawromatis P.).

\section{BUENOS PROYECTOS, BUENAS ACCIONES: BUENOS AIRES}

La problemática en el casco histórico de la ciudad de Buenos Aires es de una naturaleza distinta a los ejemplos anteriores. Mientras estuvo abandonado por el paulatino desplazamiento de las actividades terciarias, su casco histórico se encontraba en un proceso de paulatino y prolongado deterioro. Contribuía a ese estado la existencia de un gigantesco predio eriazo, situado a muy poca distancia del centro histórico y del Palacio de Gobierno.

El despertar ocurrió a principios de la década de 1990, coincidiendo con la preocupación internacional en torno a la preservación del ambiente y del patrimonio tangible e intangible. Se inició, entonces, una seguidilla de acciones específicas que iban desde la recuperación de edificios de mayor valor (como las Galerías Pacífico, por ejemplo) hasta el reciclaje de las bodegas correspondientes a Puerto Madero.

Esta última es, quizás, la empresa más emblemática de la recuperación de Buenos Aires. Con 600 hectáreas representaba una importante extensión dentro de la ciudad, equiparable a las de ciudades como Barcelona, Baltimore, Boston o Nueva York ${ }^{[9]}$. Se ofrecía la oportunidad de recuperar el casco histórico mediante la reocupación y el reciclaje de una porción generosa del mismo, pero con una visión nueva: "... si un centro quiere mantenerse vivo debe encontrar el modo de promover la localización de nuevos programas y servicios que den lugar a una nueva generación de edificios y sitios que, como tales, representan un nuevo momento de la historia de nuestras ciudades" ${ }^{[10]}$.

También debe tenerse presente que la operación de Puerto Madero se inserta en un conjunto de acciones - de envergadura más modesta- de

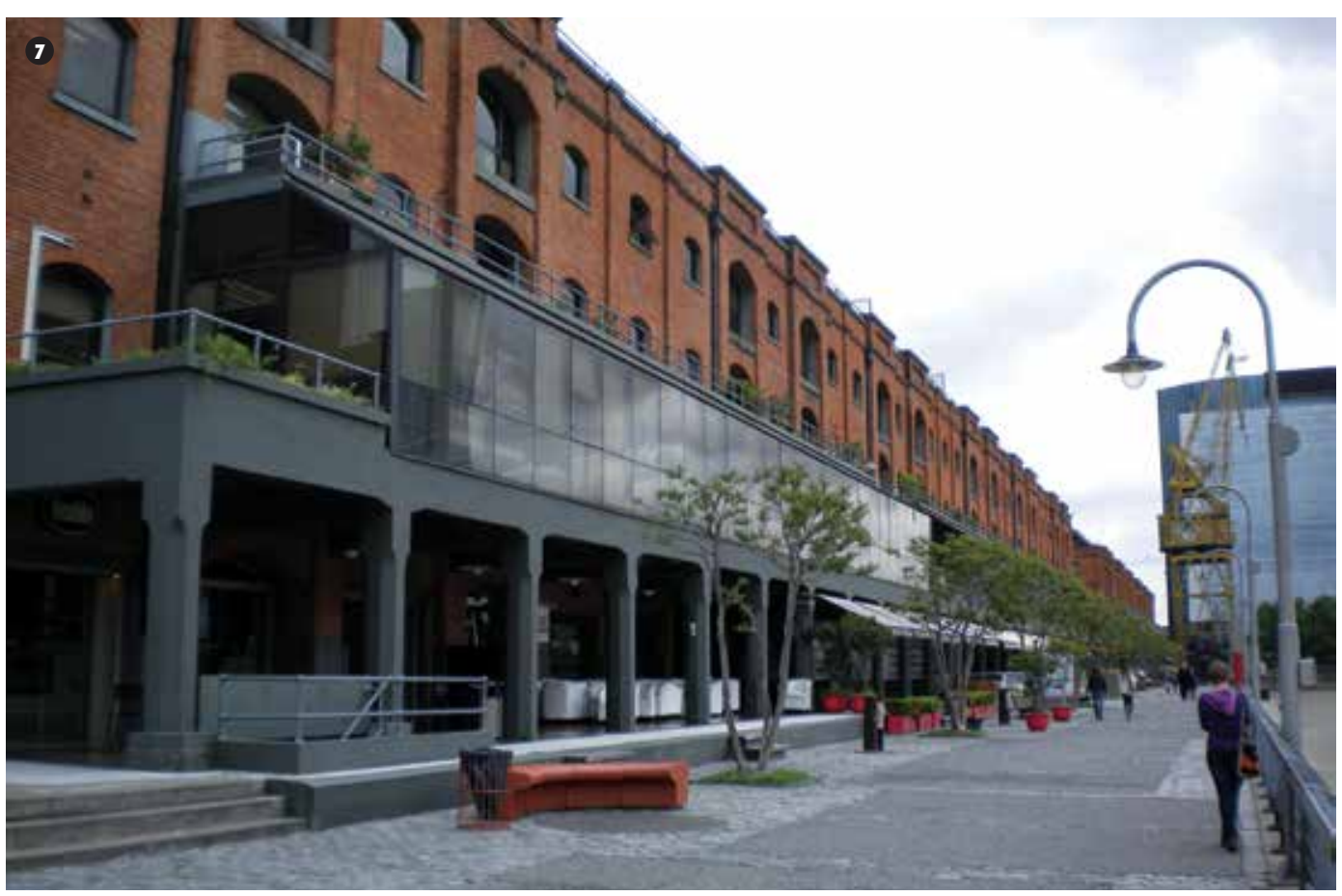

recuperación de paseos y edificios valiosos de la ciudad de Buenos Aires, acciones que se remontan a la década de 1980-1990 [1] y que se venían ejecutando de manera paciente y sistemática. Es decir, se hacía un manifiesto esfuerzo por evitar la decadencia del centro. En relación con las funciones del nuevo sector, "su tamaño y posición amplió el programa de los usos terciarios a habitacionales, abriendo un sector que, por sus cualidades ambientales, tracciona positivamente las corrientes de inversión sobre la zona sur de la ciudad (...) A poco de implementada esta política se podían reconocer sus efectos: una estrategia clara, una política firme en defensa del centro orientaba la inversión hacia sectores aledaños, localizando importantes construcciones en la zona de transición entre el microcentro y Puerto Madero" $[12]$.
Como en otros casos, la definición de una normativa específica y la práctica de un nuevo modelo de gestión facilitaban la acción recuperadora de la ciudad antigua.

Este nuevo modelo consistió en la creación de una corporación de derecho privado -Corporación Antiguo Puerto Madero-, compartida en partes iguales entre el gobierno local y el nacional. Los esfuerzos de esta corporación se centraron en la provisión y renovación de redes urbanas dirigidas al nuevo sector, para posteriormente incentivar la acción privada sobre el terreno recuperado y valorizado por la eficaz operación urbanizadora.

\footnotetext{
9] Garay, Alfredo. En Tello, María del Pilar. Op. cit., p. 121.

[10] Ormindo de Azevedo (1999). La ciudad posible. Lima. Patrimonio Cultural de la Humanidad, p. 118.

[11] Dirección General Casco Histórico, Gobierno de la Ciudad de Buenos Aires. Manual de los Procesos de Rehabilitación en Cascos Históricos, sin fecha.

[12] Tello, María del Pilar. Op. cit., p. 86
} 
8. Puerto Madero, Buenos Aires, Argentina (Fuente: Constantino Mawromatis P.)

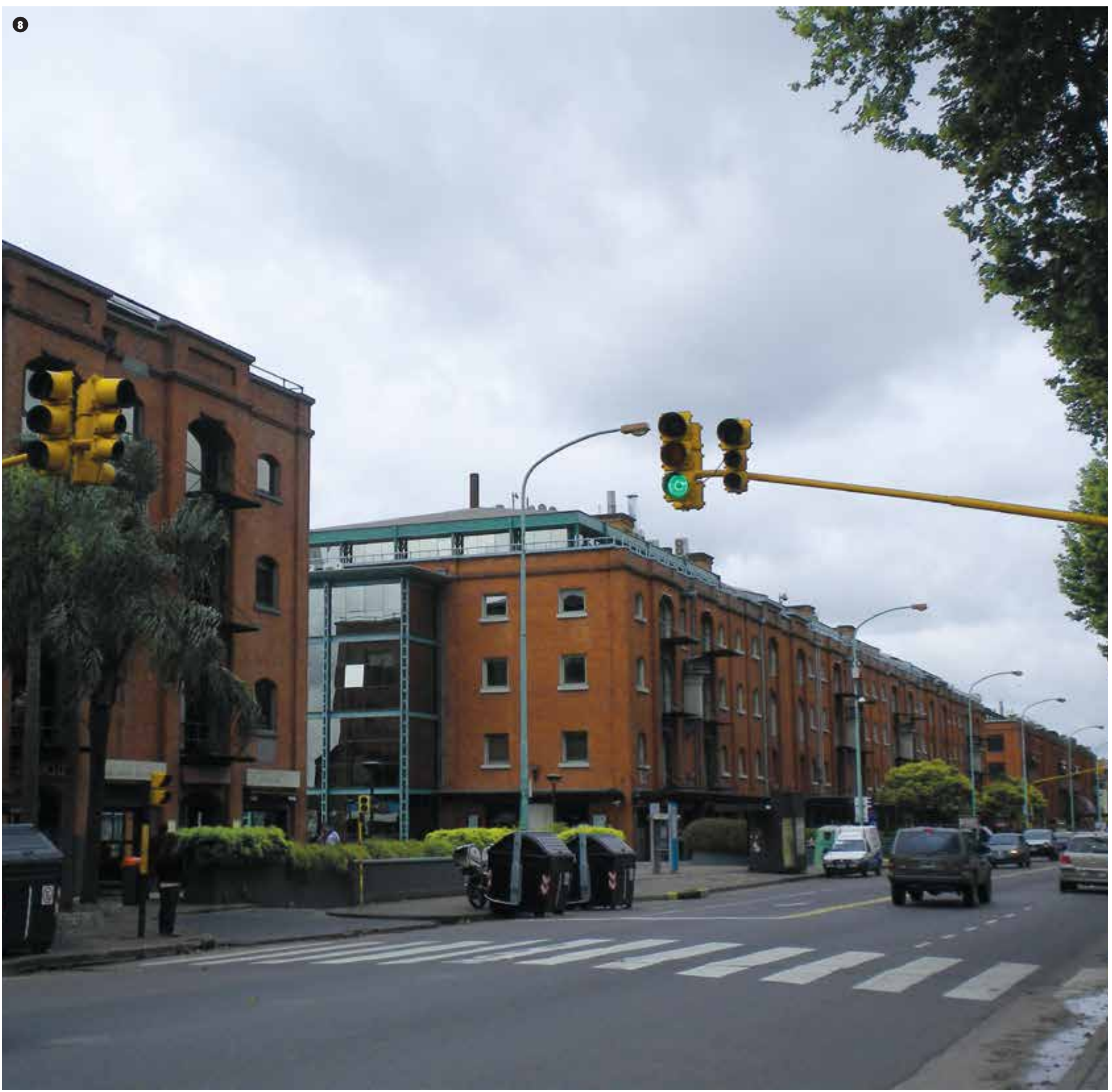


9. Casco Histórico de Salvador de Bahía, Brasil (Creative Commons, Fuente:www.flickr.com/photos/doridelsarto/).

\section{SALVADOR DE BAHÍA, UN COMPROMISO SOCIAL}

El caso de la ciudad de Bahía es característico de las ciudades iberoamericanas:

empobrecimiento del núcleo central, emigración de las clases acomodadas, pérdida de la vocación residencial, entre otros fenómenos. La peculiaridad de Bahía reside en la claridad con que se distinguían los dos circuitos económicos característicos de las ciudades brasileñas: "El circuito superior, constituido por actividades económicas formales, como bancos, industrias, comercios de importación, exportación,

mayoristas y al por menor y servicios modernos, todos integrados a nivel nacional y subsidiarios del capital multinacional (...) El circuito inferior, constituido por manufacturas, comercios y servicios informales, organizados a nivel local, responsable por el $40 \%$ al $50 \%$ del PIB, en nuestros países" ${ }^{[13]}$.

Cada uno de los circuitos tiene su correlato en su centro respectivo. El circuito inferior, que tiende a residir en el abandonado casco histórico de la ciudad, se manifiesta en el hacinamiento en edificios de interés histórico.

Este fenómeno, especialmente patente en Bahía dada la situación geográfica del Pelourinho -el barrio del casco histórico-, se enfrentó inicialmente, en la década de 1960-1970, poniendo en marcha una serie de restauraciones y reciclajes con miras a la explotación turística, para lo cual se propuso un intenso circuito de recorridos, la construcción de hoteles y la implantación de equipamientos a manera de escuelas de hotelería.

En un segundo instante se intentó, en la búsqueda de mejores resultados, una acción de tipo social en el centro histórico: la creación de programas de educación, salud, asistencia social, además de la reconversión de antiguas casonas en equipamientos sociales.

[13] de Azevedo, Ormindo. Op. cit., pp. 103-105.

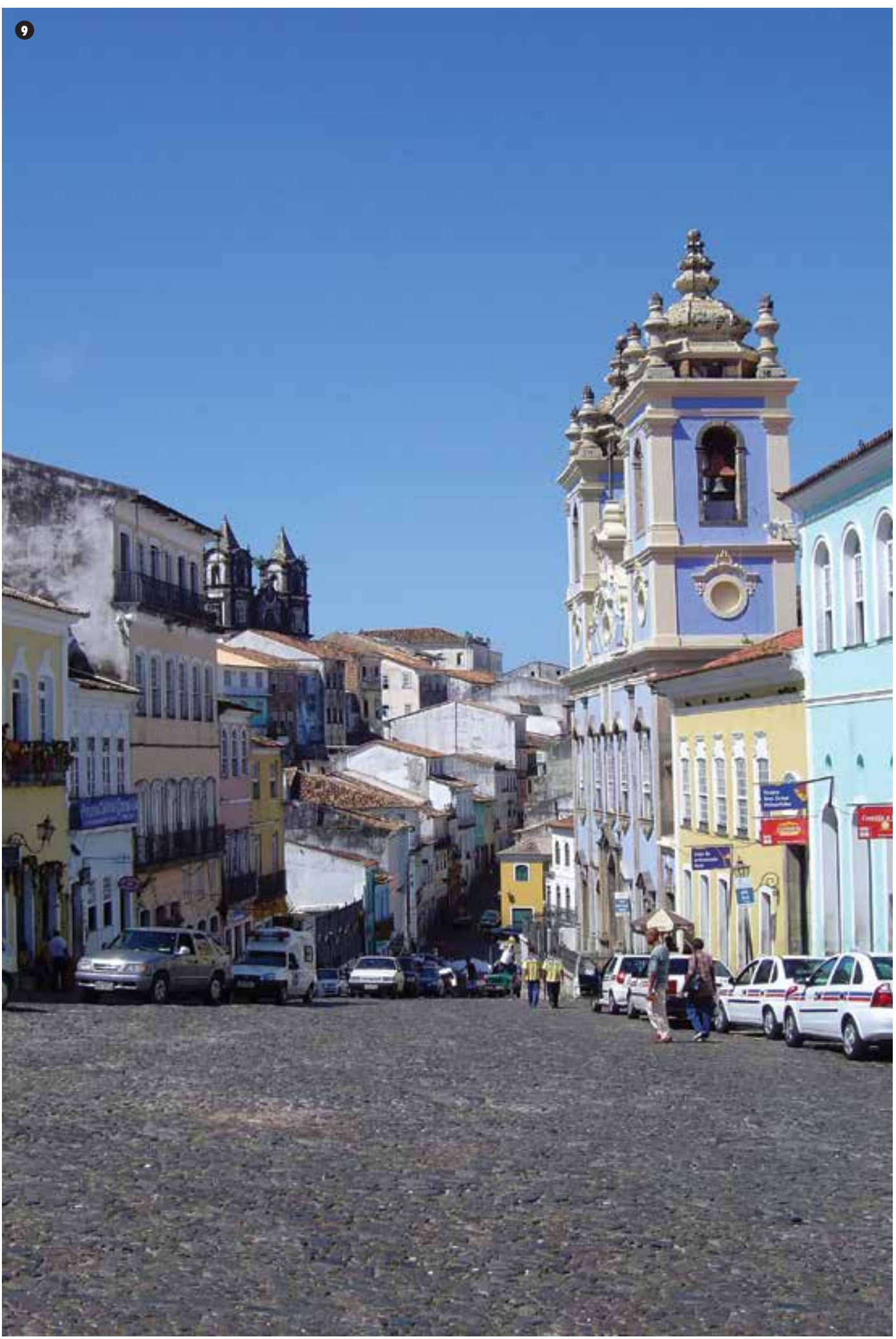


10. Casco Histórico de Salvador de Bahía, Brasil (Creative Commons, Fuente:www.flickr.com/photos/metamorfose ambulante/)

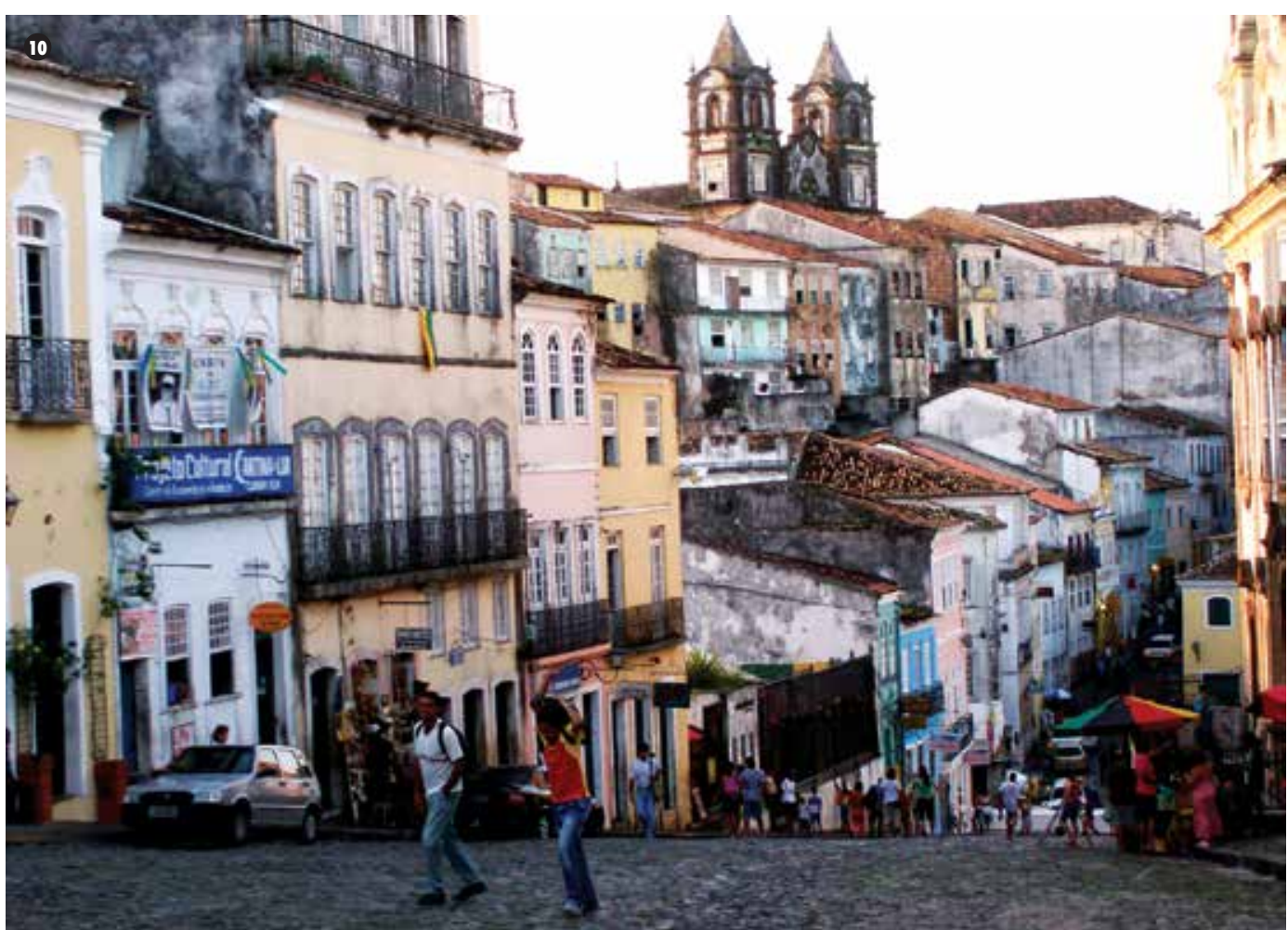

Finalmente, a principios de la década 1990-2000, una vez comprobado el éxito internacional de diversas agrupaciones e intérpretes musicales originarios del barrio histórico de Bahía, se enfrentó la recuperación del tejido histórico como la conformación de un gran equipamiento cultural.

De sus recursos propios, la autoridad estatal invirtió no menos de 30 millones de dólares. Una primera medida consistió en la indemnización de la población residente -el 95\% arrendatarios- para su emigración del casco histórico. Posteriormente se procedió a la cesión temporal, por parte de los propietarios de los derechos sobre sus inmuebles. De esta manera, la autoridad local pudo ejecutar la rehabilitación de los inmuebles para destinarlos a comercio, con costos de arriendo subsidiados por la autoridad. En términos de seguridad, se estableció una policía especial para el sector $^{[14]}$.

Aunque el resultado inmediato fue la revitalización del casco histórico gracias a la afluencia de sectores acomodados y medios para la utilización de los nuevos equipamientos, con el paso del tiempo el interés por su utilización decayó. Los antiguos habitantes del sector retornaron a él como lugar de trabajo y esparcimiento, a lo que se sumaron otros sectores modestos de la ciudad. La imposibilidad económica de tener acceso a los equipamientos turísticos creados obligó a los nuevos concurrentes al área a acudir a la versión informal del comercio ambulante de alimentos, así como al consumo de alcohol en la vía pública ${ }^{[15]}$.
El Programa de Recuperación del Distrito Histórico de Salvador (Pelourinho) se basó en una fuerte intervención oficial dentro de una sección reducida del área céntrica.

A partir de 1993, una institución pública-el Instituto del Patrimonio Cultural e Histórico de Bahía-, con financiamiento del gobierno del Estado, consiguió rehabilitar más de 300 edificios localizados en 16 manzanas dentro de área céntrica de la ciudad de Salvador (zona que ha sido declarada Patrimonio Cultural Mundial por la UNESCO).

Utilizando las manzanas como unidad de rehabilitación, el Instituto ejecutó todas las obras, tanto en propiedades públicas como privadas, ofreciendo a los arrendatarios la opción de obtener una compensación económica por desalojar el edificio. Hasta ahora, el Instituto ha logrado rehabilitar edificios y promover actividades de turismo y recreación. Sin embargo, se ha recuperado solo parcialmente los costos de rehabilitación; tampoco se ha producido una diversificación importante de las actividades económicas y residenciales.

El costo para el presupuesto público ha sido enorme. Todavía no se ha medido los efectos de esta operación: hasta qué punto se logra promover la diversificación de las actividades económicas, más allá del turismo; o si los actuales usuarios tendrán la capacidad de sustentar, a largo plazo, el esfuerzo inicial.

Del caso de Salvador de Bahía se puede concluir que, aunque positiva en su enfoque de enfrentar el casco histórico de la ciudad como una totalidad antes que un repertorio de acciones puntuales, en esta operación el compromiso de los actores sociales y políticos es solo parcial: la ausencia de una mayor integración con las autoridades locales y federales augura una continuidad incierta en los intentos por recuperar el centro histórico ${ }^{[16]}$.
Tello, María del Pilar. Op. cit., pp. 107-109.
Tello, María del Pilar. Op. cit., p. 112.

[15] Tello, María del Pilar. Op. cit., p. 112. 


\section{APUNTES FINALES}

Se sabe que no existen opciones radicales químicamente puras al momento de intervenir un fragmento de ciudad. Lo difícil es tender a la solución sensible, a aquella que no menoscaba ni desbarata la ciudad. Por suerte, las posiciones extremas solo se adoptan en raras oportunidades, pero son suficientes para contribuir a un resultado híbrido y a menudo caótico.

Mientras la ciudad no esté enteramente regulada existirán puntos vulnerables que, tarde o temprano, la irán desarticulando. ¿̇Es posible comenzar ahora a regular la ciudad? Y si se regula, ¿̇tenemos la certeza de que obtendremos una ciudad armónica? No. No es fácil garantizar calidad cuando los responsables de la futura ciudad -mandante, proyectista y autoridadesdesconocen o ignoran voluntariamente los códigos del buen hacer y las claves de un amable escenario urbano.

Aunque, por motivos diferentes, el sector privado también invierte en la conservación. Es usual que las empresas de vocación corporativa elijan edificios de valor histórico para utilizarlos como sede de sus operaciones. Se asocia con arraigo y con prestigio. La comunidad agradece que le ofrezcan un monumento enteramente recuperado. Como siempre, uno de los peligros se remite a la calidad de la intervención.

El otro peligro -tanto o mayor que el anteriores que los propietarios, desencantados, sin incentivos, solo esperen la lenta extinción del bien, ilusionados con la idea de que el terreno eriazo se convertirá en una lucrativa playa de aparcamientos.

La rehabilitación de barrios y sectores desmejorados resulta, a todas luces, beneficioso: atrae la actividad turística y la Municipalidad que lo prohija recibe más ingresos. Pero también trae consigo estimulantes efectos: sube el precio del suelo y de los inmuebles que se posan encima de él. Es el proceso que impulsa las actividades económicas en el área y que, en último término, favorece a las arcas del fisco y de los propietarios de la tierra.

\section{BIBLIOGRAFÍA}

Libros

Aymonino, Carlo (1981). El significado de las ciudades. H. Blume Ediciones, Madrid (ed. Original: II sinificato delle cità), $364 \mathrm{pp}$.

Aymonino, Carlo (1972). Orígenes y desarrollo de la ciudad moderna. Editorial Gustavo Gili, Barcelona, 329 pp.

Brolin, Brent C. (1980). La arquitectura de integración. Armonización entre edificios antiguos y modernos. Biblioteca de Arquitectura y Construcción, Ediciones Ceac, Barcelona

Capitel, Antón (1988). Metamorfosis de monumentos y teorías de la restauración. Editorial Alianza, Madrid.

Chueca Goitia, Fernando (1977). Breve historia del urbanismo. Alianza Editorial S.A., Madrid, 241 pp.

De Gracia, Francisco (2001). Construir en lo construido La arquitectura como modificación. Editorial Nerea, $3^{\text {ra }}$ edición revisada, Madrid, 324 pp.

Giovanetti, Francesco (1993). Estrategias de renovación en centros históricos. Valencia.

Gutiérrez, Ramón (1983). Arquitectura y Urbanismo en Iberoamérica. Manuales Arte Cátedra, Madrid.

Gutiérrez, Ramón (1977). Arquitectura latinoamericana. Textos para la reflexión y la polémica. Epígrafe Editores S.A., $1^{\text {ra }}$ edición, Lima.

Hardoy, J. E.; Gutman, M. V. (1992). Impacto de la urbanización en los centros históricos de iberoamérica. Editorial MAPFRE, Madrid.

Romero, José Luis; Gutiérrez Girardot, Rafael (2004). Las ciudades y las ideas. Siglo XXI editores Argentina, $2^{\text {da }}$ edición, Buenos Aires, 532 pp.

Tello, María Del Pilar (editora) (1999). La ciudad posible. Lima. Patrimonio Cultural de la Humanidad, Lima.

Waisman, Marina (1993). El interior de la historia. Historiografía arquitectónica para uso de latinoamericanos. Escala, Bogotá, 141 pp.

Waisman, Marina (1997). La estructura histórica del entorno. Ediciones Nueva Visión, Buenos Aires, 288 pp.

Revistas, Diarios e Informes

Álvarez Mora, Alfonso (2000). "La cuestión de los centros históricos. Generaciones de planes y políticas urbanísticas recientes". Revista Pensar la ciudad, vitalidad y límites del plan urbanístico, Instituto de Urbanística de la Universidad de Valladolid, Secretariado de Publicaciones, Valladolid.
De Azevedo, Ormindo (1999). En "La ciudad posible. Lima, Patrimonio Cultural de la Humanidad" (Editora: María del Pilar Tello), Lima, pp. 103-105.

Dirección General Casco Histórico, Gobierno de la Ciudad de Buenos Aires. Manual de los Procesos de Rehabilitación en Cascos Históricos. Buenos Aires, sin fecha.

Gutiérrez, Ramón (1983). Arquitectura y urbanismo en iberoamérica. Ediciones Cátedra, Madrid, pp. 227. 228.

Publicaciones electrónicas

Centros Históricos żherencia del pasado o construcción del presente? Agentes detonantes de un nuevo esquema de ciudad, artículo publicado en: Scripta Nova: Revista electrónica de Geografía y Ciencias Sociales / Universidad de Barcelona. ISSN: $1138-$ 9788. Depósito Legal: B. 21.741-98. Vol. IX, núm. 194 (39), 1 de agosto de 2005 [http://www.ub.es/ geocrit/sn/sn-194-39.htm]

Historiografía urbana en Latinoamérica: Del positivismo al postmodernismo, artículo publicado por Arturo Almandoz, en la página del Departamento de Historia de la Universidade Estadual de Maringá [http://www.dhi.uem.br/publicacoesdhi/dialogos/ volume01/vol7_atg2.htm].

Paisajes urbanos (Toledo/Castilla-La Mancha), artículo publicado por Isabel del Río Lafuente, en la página de Recursos didácticos en geografía, del Instituto de Economía y Geografía de Madrid [http://www.ieg csic.es/Age/recur_didacticos/].

Sitios consultados

Alejandro Suárez, Ciudadan@latin@[http://habitat. aq.upm.es/boletin/n23/aasua.html].

Rehabilitación de áreas centrales: problemas y oportunidades. Estrategias e Instrumentos de gestión urbana para el desarrollo sostenible en América Latina y el Caribe, División de Medio Ambiente y Asentamientos Humanos - Cooperazione Italiana [http://www.eclac.cl/dmaah/guds/renov.htm].

http://revistaurbanismo.uchile.cl/CDA/urb_simple/0,1310,SC ID\%253D3809\%2526ISID\%253D257\%2526IDG\%253 D1\%2526ACT\%253D0\%2526PRT\%253D3807,00.html

www.coachi.com / principal 1.htm

www.plataformaurbana.cl/copp/albums/userpics/10008/ Astaburuaga.pdf

www.ucentral.cl/Sitio\%20web\%202003/Revista\%20 Farq/002.htm 